\title{
Utilization of a Wheat50K SNP Microarray-Derived High-Density Genetic Map for QTL Mapping of Plant Height and Grain Traits in Wheat
}

\author{
Dongyun Lv ${ }^{1,+}$, Chuanliang Zhang ${ }^{1,+}$, Rui $\mathrm{Yv}^{1}$, Jianxin Yao ${ }^{1}$, Jianhui $\mathrm{Wu}^{1}$, Xiaopeng Song ${ }^{2}$, Juntao Jian ${ }^{3}$, \\ Pengbo Song ${ }^{1}$, Zeyuan Zhang ${ }^{1}$, Dejun Han ${ }^{1, *}$ and Daojie Sun ${ }^{1, *}$
}

check for

updates

Citation: Lv, D.; Zhang, C.; Yv, R.; Yao, J.; Wu, J.; Song, X.; Jian, J.; Song, P.; Zhang, Z.; Han, D.; et al. Utilization of a Wheat50K SNP Microarray-Derived High-Density Genetic Map for QTL Mapping of Plant Height and Grain Traits in Wheat. Plants 2021, 10, 1167. https://doi.org/10.3390/plants10061167

Academic Editor:

Abdelmajid Kassem

Received: 17 April 2021

Accepted: 26 May 2021

Published: 8 June 2021

Publisher's Note: MDPI stays neutral with regard to jurisdictional claims in published maps and institutional affiliations.

Copyright: (c) 2021 by the authors. Licensee MDPI, Basel, Switzerland. This article is an open access article distributed under the terms and conditions of the Creative Commons Attribution (CC BY) license (https:/ / creativecommons.org/licenses/by/ $4.0 /)$.
1 College of Agronomy, Northwest A\&F University, Xianyang 712100, China; lvdongyun1102@163.com (D.L.); wyanan@nwafu.edu.cn (C.Z.); $18404969211 @ 163 . c o m$ (R.Y.); bilwqz@163.com (J.Y.); wujh@nwafu.edu.cn (J.W.); wheat5200stem@163.com (P.S.); 18238768351@163.com (Z.Z.)

2 Zhumadian Academy of Agricultural Sciences, Zhumadian 463000, China; weiduxp@163.com

3 Nanyang Academy of Agricultural Sciences, Nanyang 473000, China; jjt312024501@163.com

* Correspondence: handj@nwafu.edu.cn (D.H.); chinawheat@163.com (D.S.)

+ These authors have equal contribution.

\begin{abstract}
Plant height is significantly correlated with grain traits, which is a component of wheat yield. The purpose of this study is to investigate the main quantitative trait loci (QTLs) that control plant height and grain-related traits in multiple environments. In this study, we constructed a high-density genetic linkage map using the Wheat50K SNP Array to map QTLs for these traits in 198 recombinant inbred lines (RILs). The two ends of the chromosome were identified as recombination-rich areas in all chromosomes except chromosome 1B. Both the genetic map and the physical map showed a significant correlation, with a correlation coefficient between 0.63 and 0.99 . However, there was almost no recombination between 1RS and 1BS. In terms of plant height, 1RS contributed to the reduction of plant height by $3.43 \mathrm{~cm}$. In terms of grain length, 1RS contributed to the elongation of grain by $0.11 \mathrm{~mm}$. A total of 43 QTLs were identified, including eight QTLs for plant height (PH), 11 QTLs for thousand grain weight (TGW), 15 QTLs for grain length (GL), and nine QTLs for grain width (GW), which explained $1.36-33.08 \%$ of the phenotypic variation. Seven were environment-stable QTLs, including two loci (Qph.nwafu-4B and Qph.nwafu-4D) that determined plant height. The explanation rates of phenotypic variation were 7.39-12.26\% and 20.11-27.08\%, respectively. One QTL, Qtgw.nwafu$4 B$, which influenced TGW, showed an explanation rate of $3.43-6.85 \%$ for phenotypic variation. Two co-segregating KASP markers were developed, and the physical locations corresponding to KASP_AX-109316968 and KASP_AX-109519968 were 25.888344 MB and 25.847691 MB, respectively. Qph.nwafu-4B, controlling plant height, and Qtgw.nwafu-4B, controlling TGW, had an obvious linkage relationship, with a distance of 7-8 cM. Breeding is based on molecular markers that control plant height and thousand-grain weight by selecting strains with low plant height and large grain weight. Another QTL, Qgw.nwafu-4D, which determined grain width, had an explanation rate of 3.43-6.85\%. Three loci that affected grain length were Qgl.nwafu-5A, Qgl.nwafu-5D.2, and Qgl.nwafu-6B, illustrating the explanation rates of phenotypic variation as $6.72-9.59 \%, 5.62-7.75 \%$, and $6.68-10.73 \%$, respectively. Two QTL clusters were identified on chromosomes 4B and 4D.
\end{abstract}

Keywords: wheat; plant height; grain traits; Wheat50K; genetic map; QTL

\section{Introduction}

Wheat (Triticum aestivum L.) is a major food crop globally, providing carbohydrates and protein for $35 \%$ of the global population. It is estimated that wheat production will increase by more than $70 \%$ in the next 30 years to meet the needs of the growing population [1]. To ensure global food security, genetic improvement of food production will be one of the main goals of wheat breeding programs [2-4]. 
Both 1000-grain weight (TGW) and the genetic improvement of related traits, which play a vital role in wheat yield, are applicable to increasing wheat yield. TGW is mainly affected by grain morphological parameters, such as grain length and grain width [4-6]. TGW-related genes, including sucrose synthase genes, encode cell wall invertase and cytokinin oxidase/dehydrogenase. The sucrose synthase genes TaSus1-7A, $-7 B$ and TaSus2$2 A,-2 B$ determine TGW and grain size $[7,8], \mathrm{TaGW} 2-6 A,-6 B$ the grain width $[9,10]$, and TaGS-D1 the grain size [11]. TaCwi-A1 encodes cell wall invertase [12], TaCKX6-D1 encodes cytokinin oxidase/dehydrogenase [13], and TaGASR-A1 is a putative Snakin/GASA protein associated with grain length (GL) (Dong et al., 2014). The inheritance of grain traits is relatively stable, forming a higher heritability than overall yield [14]. The method is suitable for QTL analysis of wheat samples planted and collected from different places and years, and a stable QTL can be retrieved and detected. Over the past 20 years, more than 150 QTLs related to TGW, grain length, and grain width have been identified, which are distributed on 21 chromosomes of wheat [5,15-45]. Some studies have shown that there is a significant positive correlation between plant height and TGW [19,32,33,39,46,47]. The application of Rht1 (RHT-B1b) and Rht2 (RHT-D1b) in the 1960s set off a green revolution in wheat breeding. So far, $25 R h t$ genes have been identified in wheat [48,49]. Amongst these 25 genes, Rht1 and Rht2 are dwarfing genes that show insensitivity to gibberellins located on chromosomes 4BS and 4DS, respectively [13]. The wild alleles Rht-B1a and Rht-D1a also have a significant positive correlation with TGW [32,50]. Another gene, called Rht8, is sensitive to gibberellins for reducing plant height and is located on the 2DS chromosome. $R h t 8$ is another widely applied dwarfing gene that has no obvious negative effect on TGW, but affects panicle length. Thus, Rht8 is a typical pleiotropism gene [6,51]. The genetic relationship can be investigated by targeting gene loci related to TGW and plant height, obtained by QTL mapping [30,52].

QTL genetic mapping is a crucial means to analyze functional loci [28]. Constructing a saturated genetic map is the key to QTL mapping, and molecular markers are the genetic map carrier. Triticum aestivum L. is a typical allohexaploid (AABBDD) composed of three subunits, and it represents the largest crop genome. Moreover, it is also the genome with the highest proportion of repetitive sequences such as transposable elements (84.7\%) (IWGSC2018). Multitudes of SNP markers bear abundant polymorphism [53], and mapping results are quite advantageous in terms of accuracy and precision, especially for QTL mapping of quantitative traits [53,54]. By constructing a high-density genetic map to target the SNPs' genetic and physical loction, collinearity analysis is performed, and then the recombination rate in different regions of the chromosome can be judged. After comparing the genetic and physical distances between adjacent markers, the relative changes of recombination rates in each chromosome can be further investigated and analyzed. The range of the mating population required for a recombination event in a specific region can be estimated. Scientific and accurate estimation for breaking the chain of specific target areas can be provided, and accurate judgments for evaluating genetic linkage drag, together with guidance for improving breeding efficiency, can be achieved [54,55].

Until now, couples of common wheat SNP microarrays, including Wheat9K [56], Wheat90K [37,57,58], Wheat820K [59], Wheat660K (http://bioservices.capitalbio.com/ index.shtml) $[37,57,58]$, and the Wheat55K SNP array, have been developed based on the $660 \mathrm{~K} \mathrm{SNP}$ array [60-65].The Wheat50K SNP array is a high-efficiency genotyping technology completed by the Institute of Crop Science of the Chinese Academy of Agricultural Sciences and Affymetrix. The technology was developed using high-quality SNP markers selected from Wheat $90 \mathrm{~K}$ SNP arrays, 660K SNP arrays, and 35K SNP arrays. In the $50 \mathrm{~K}$ SNP array, there are 135 functional markers and 700 SNP markers closely linked to known QTLs [66]. The functional markers covering ten TGW-related genes and two plant height-related genes are shown in Table S1.

In this study, a Kompetitive allele-specific PCR (KASP) marker was used, which is a polymerase chain reaction-based (PCR) technology using fluorescence for single nucleotide polymorphism (SNP) and small insertion and deletion (InDel). KASP markers have the 
advantage of a low error rate and a relatively low cost compared to other SNP genotyping platforms such as TaqMan systems. According to the method of Ma et al. [63], SNPs located in the main QTL interval were selected to develop KASP markers.

This project aims to determine the chromosome recombination rates in different regions using collinearity analysis of the genetic positions and physical locations of the SNP markers. By mapping the environment-stable QTL region of grain-related traits, whether corresponding loci are located in the recombination-rich or recombination-barren area can be confirmed, and a reasonable judgment for further fine mapping can be fulfilled. By traits and linkage analysis of the relationship between plant height and grain traits, useful insights for the next steps of molecular breeding can also be provided.

\section{Results}

\subsection{Agronomic Traits Analysis}

As was shown in Table 1 , significant differences when $p=0.01$ in the four environments appeared in relation to the plant height, TGW, grain length, and grain width of the twoparent materials. In Table 1 and Figure S1, we can see that fluctuations occurred in the same traits in different environments, indicating that these four traits were easily affected by the environment. The agronomic traits failed to accord with a strictly normal distribution $(p<0.05)$. The trait heritability values of plant height, TGW, grain length, and grain width were $0.73,0.62,0.61$, and 0.72 , respectively. As can be seen, those of plant height and grain width were relatively high.

Table 1. Statistical analysis of parent and RIL lines for traits.

\begin{tabular}{|c|c|c|c|c|c|c|c|c|}
\hline Traits & Environment & Xinong1376 & Xiaoyan81 & Mean \pm SD & Minimum & Maximum & $p$-Value & Heritability \\
\hline \multirow[t]{4}{*}{$\begin{array}{l}\text { Plant } \\
\text { height }\end{array}$} & $19 \mathrm{NY}$ & 65.25 & $77.75^{* *}$ & $67.08 \pm 13.78$ & 32.2 & 96.8 & $2.19 \times 10^{-3}$ & \multirow[t]{4}{*}{0.73} \\
\hline & $20 N Y$ & 68.24 & 81.22 ** & $80.03 \pm 14.43$ & 40.2 & 109.8 & $5.66 \times 10^{-6}$ & \\
\hline & 19YL & 68.36 & $78.23^{* *}$ & $65.78 \pm 12.78$ & 34.6 & 90.9 & $6.14 \times 10^{-4}$ & \\
\hline & $20 \mathrm{YL}$ & 72.33 & $83.25^{* *}$ & $72.24 \pm 15.08$ & 38.3 & 109.2 & $3.82 \times 10^{-2}$ & \\
\hline \multirow[t]{4}{*}{$\begin{array}{l}\text { Thousand } \\
\text { Grain } \\
\text { Weight }\end{array}$} & $19 N Y$ & $41.35^{* *}$ & 36.23 & $40.72 \pm 4.37$ & 27.81 & 52.19 & $1.12 \times 10^{-1}$ & \multirow[t]{4}{*}{0.62} \\
\hline & $20 N Y$ & $42.13^{* *}$ & 39.48 & $42.62 \pm 4.51$ & 26.28 & 51.76 & $1.24 \times 10^{-3}$ & \\
\hline & 19YL & $44.32 * *$ & 41.75 & $45.32 \pm 4.41$ & 34.22 & 55.05 & $2.80 \times 10^{-2}$ & \\
\hline & $20 \mathrm{YL}$ & $46.23^{* *}$ & 42.32 & $45.21 \pm 4.40$ & 29.5 & 54.83 & $3.68 \times 10^{-1}$ & \\
\hline \multirow{4}{*}{$\begin{array}{l}\text { Grain } \\
\text { length }\end{array}$} & $19 N Y$ & $7.12 * *$ & 6.87 & $7.23 \pm 0.37$ & 6.27 & 8.04 & $3.93 \times 10^{-2}$ & \multirow[t]{4}{*}{0.61} \\
\hline & $20 N Y$ & $7.32 * *$ & 6.75 & $7.14 \pm 0.35$ & 6.34 & 8.03 & $6.79 \times 10^{-2}$ & \\
\hline & 19YL & $7.51^{* *}$ & 7.24 & $7.44 \pm 0.34$ & 6.68 & 8.23 & $1.81 \times 10^{-2}$ & \\
\hline & 20YL & $7.36^{* *}$ & 7.14 & $7.51 \pm 0.38$ & 6.67 & 8.51 & $1.96 \times 10^{-1}$ & \\
\hline \multirow{4}{*}{$\begin{array}{l}\text { Grain } \\
\text { width }\end{array}$} & $19 N Y$ & 3.31 & 3.21 & $3.37 \pm 0.15$ & 2.88 & 3.69 & $1.45 \times 10^{-3}$ & \multirow[t]{4}{*}{0.72} \\
\hline & $20 N Y$ & $3.88^{* *}$ & 3.62 & $3.45 \pm 0.18$ & 2.81 & 3.83 & $2.18 \times 10^{-3}$ & \\
\hline & 19YL & $3.51^{* *}$ & 3.28 & $3.60 \pm 0.16$ & 3.11 & 3.9 & $1.38 \times 10^{-2}$ & \\
\hline & $20 Y L$ & $3.66^{* *}$ & 3.42 & $3.60 \pm 0.16$ & 3.16 & 3.95 & $3.02 \times 10^{-3}$ & \\
\hline
\end{tabular}

Note: ${ }^{* *}$ represents a significant difference between the two parents when $p=0.01$.

As was shown in Figure S1, there was a significant positive correlation between the same traits and different environments when $p=0.001$. The correlation between different years in the same place was higher than that in other combinations, indicating that a high degree of environmental similarity was present in the same place but in different years. The correlation between plant height and grain length was negative, but there was a significant positive correlation between TGW and grain width. TGW had a significant positive correlation with the other three traits, and a higher correlation with grain width than that with other traits. The correlation between grain length and grain width was different in different environments. 


\subsection{Construction of a Genetic Map}

\subsubsection{Description and Illustration of a Genetic Map}

66,832 markers were subject to polymorphism analysis of population genotype by $50 \mathrm{~K}$ gene microarray. A total of 19,601 SNP markers with differences were screened in the derived RIL populations of Xinong1376 and Xiaoyan81, while the remaining 15,822 markers were filtered by Chi-square test, and redundant markers were eliminated using the bin function of IciMapping. A total of 3136 bin markers, including 15,576 SNP markers, were eventually anchored to the genetic map. In addition, the genotyping, polymorphism marker, data filtering, physical map, genetic map, and bin map are all shown and illustrated in Table S2. Based on the 660K chip labeling, the SNP markers that differed between the two parents were detected and stored in Figure S2. The total length of the linkage map was $4512.79 \mathrm{cM}$, the average map distance was $1.44 \mathrm{cM}$, and the maximum gap was $26.86 \mathrm{cM}$, which covered 21 wheat chromosomes. According to linkage lengths in the homologous groups, their sequence in descending order was the fifth, the seventh, the third, the second, the fourth, the sixth, and the first. The linkage lengths were $813.14 \mathrm{cM}, 794.35 \mathrm{cM}, 703.96$ $\mathrm{cM}, 631.98 \mathrm{cM}, 563.99 \mathrm{cM}, 537.27 \mathrm{cM}$, and $468.12 \mathrm{cM}$, and the numbers of bin markers were 621 (2947 SNP markers included), 549 (2193 SNP markers included), 524 (2846 SNP markers included), 327 (1865 SNP markers included), 393 (2002 SNP markers included), 372 (1865 SNP markers included), and 272 (2016 SNP markers included), respectively.

The numbers of bin markers located in wheat $\mathrm{A}, \mathrm{B}$, and $\mathrm{D}$ chromosome groups were 1231,1197 , and 708, respectively. The linkage lengths were $1703.69 \mathrm{cM}, 1298.23 \mathrm{cM}$ and $1510.87 \mathrm{cM}$, and the average map distances were $1.38 \mathrm{cM}, 1.08 \mathrm{cM}$, and $2.13 \mathrm{cM}$, respectively. Molecular markers in the D genome were no more than those in the other two subgroups. In addition, the longest linkage group corresponding to chromosome $3 \mathrm{~A}$ was $312.11 \mathrm{cM}$, and the shortest corresponding to chromosome 1D was $130.85 \mathrm{cM}$. The maps of each linkage group were shown and illustrated in Table 2 and Figure S2.

\subsubsection{Collinearity Analysis of the Genetic Map}

In this research, the genetic map and the collinearity map of the reference genome were analyzed as follows: The whole chromosome was included in the genetic map, the genetic map and the physical map were collinear, and the linkage map and the physical map were not linearly related. The recombination exchange on chromosomes was unbalanced, and the collinear diagrams of other chromosomes except for chromosome 1B appeared by and large S-shaped. The genetic positions of chromosomes increased linearly with the increase in physical locations, and the rest of the genetic positions aligned constantly with the increase in physical locations. This indicated that the two ends of the chromosome were recombination-rich areas and that the middle region was a recombination-barren area. A significant correlation of the genetic map and the physical one appeared when $p=$ 0.001 , the correlation coefficient ranged from 0.63 to 0.99 , and the correlation coefficient of chromosome $1 \mathrm{~B}$ was 0.63 . The distribution presentation of bin markers on the reference genome showed that the number of bin markers on both ends of the chromosome was significantly higher than that of the middle region. The recombination rate of the two sides with a U-shaped distribution was significantly higher than that of the middle region, which confirmed that the ends of the chromosome were recombination-rich areas and the middle was the recombination-barren area. The reason for these findings was the inhibitory effect of centromere recombination.

No markers could be detected in the middle regions (more than $200 \mathrm{MB}$ ) of chromosomes 1D, 5A, and 6A. However, the linkage group was not divided into two parts in these regions, which were supposed to be recombination-barren regions. For nine chromosomes (2D, 3D, 5A, 5B, 5D, 6A, 6D, 7A and 7D), each chromosome included two linkage groups. For different linkage groups corresponding to the same chromosome, the grouping regions all appeared at both ends of the chromosome as the recombination-rich area, and the physical distance between the markers was less than $30 \mathrm{MB}$. 
The collinearity map of chromosome 1B from 0 to $480 \mathrm{MB}$ presented as an L-type curve. Although the gradual numerical values of physical location increased, the genetic distances were almost unchanged, and thus homologous recombination hardly occurred in the region. Xinong1376 belonged to 1BL/1RS translocation line, 1RS and 1BS hardly recombined, and the centromere's inhibition of recombination happened in the middle region, making the collinearity map L-shaped.

Table 2. Single-nucleotide polymorphism (SNP) marker statistics about distribution and density on 21 wheat chromosomes derived from crossing between Xinong1376 and Xiaoyan81.

\begin{tabular}{|c|c|c|c|c|c|c|c|c|}
\hline Chromosome & $\begin{array}{l}\text { Linkage } \\
\text { Group }\end{array}$ & Length(cM) & $\begin{array}{c}\text { Maker } \\
\text { Numbers }\end{array}$ & $\begin{array}{c}\text { Bin } \\
\text { Number }\end{array}$ & $\begin{array}{l}\text { Insinuation } \\
\text { Markers }\end{array}$ & $\begin{array}{c}\text { Maximum } \\
\text { Clearance }\end{array}$ & $\begin{array}{c}\text { Average } \\
\text { Bin }\end{array}$ & $\begin{array}{c}\text { Bin } \\
\text { Density }\end{array}$ \\
\hline $1 \mathrm{~A}$ & LG1A & 192.66 & 1064 & 112 & 1045 & 25.68 & 1.72 & 0.58 \\
\hline $1 \mathrm{~B}$ & LG1B & 144.61 & 558 & 118 & 447 & 26.86 & 1.23 & 0.82 \\
\hline $1 \mathrm{D}$ & LG1D & 130.85 & 394 & 42 & 336 & 18.01 & 3.12 & 0.32 \\
\hline $2 \mathrm{~A}$ & LG2A & 215.97 & 951 & 140 & 940 & 23.46 & 1.54 & 0.65 \\
\hline $2 B$ & LG2B & 244.43 & 676 & 173 & 597 & 25.44 & 1.41 & 0.71 \\
\hline \multirow[t]{2}{*}{$2 \mathrm{D}$} & LG2D.1 & 132.89 & 161 & 48 & 154 & 25.42 & 2.77 & 0.36 \\
\hline & LG2D.2 & 38.69 & 77 & 11 & 75 & 10.06 & 3.52 & 0.28 \\
\hline $3 \mathrm{~A}$ & LG3A & 311.23 & 1322 & 285 & 1301 & 16.8 & 1.09 & 0.92 \\
\hline $3 B$ & LG3B & 160.61 & 487 & 144 & 458 & 12.59 & 1.12 & 0.9 \\
\hline \multirow[t]{2}{*}{$3 \mathrm{D}$} & LG3D.1 & 17.46 & 38 & 8 & 36 & 13.71 & 2.18 & 0.46 \\
\hline & LG3D.2 & 214.66 & 999 & 87 & 1026 & 22.84 & 2.47 & 0.41 \\
\hline $4 \mathrm{~A}$ & LG4A & 228.42 & 614 & 123 & 592 & 24.85 & 1.86 & 0.54 \\
\hline $4 \mathrm{~B}$ & LG4B & 169.56 & 1185 & 193 & 1156 & 8.57 & 0.88 & 1.14 \\
\hline $4 \mathrm{D}$ & LG4D & 166.01 & 203 & 77 & 199 & 16.52 & 2.16 & 0.46 \\
\hline \multirow[t]{2}{*}{$5 \mathrm{~A}$} & LG5A.1 & 234.18 & 969 & 169 & 963 & 16.26 & 1.39 & 0.72 \\
\hline & LG5A.2 & 52.94 & 139 & 39 & 134 & 9.87 & 1.36 & 0.74 \\
\hline \multirow[t]{2}{*}{$5 B$} & LG5B.1 & 68.44 & 682 & 88 & 675 & 8.09 & 0.78 & 1.29 \\
\hline & LG5B.2 & 172.4 & 538 & 164 & 529 & 15.43 & 1.05 & 0.95 \\
\hline \multirow[t]{2}{*}{$5 \mathrm{D}$} & LG5D.1 & 223.58 & 192 & 119 & 171 & 13.69 & 1.88 & 0.53 \\
\hline & LG5D.2 & 61.6 & 427 & 42 & 415 & 8.03 & 1.47 & 0.68 \\
\hline \multirow[t]{2}{*}{$6 \mathrm{~A}$} & LG6A.1 & 112.71 & 154 & 50 & 137 & 20.91 & 2.25 & 0.44 \\
\hline & LG6A.2 & 54.95 & 161 & 36 & 151 & 17.46 & 1.53 & 0.66 \\
\hline $6 \mathrm{~B}$ & LG6B & 167.65 & 852 & 188 & 783 & 7.7 & 0.89 & 1.12 \\
\hline \multirow[t]{2}{*}{$6 \mathrm{D}$} & LG6D.1 & 31.08 & 34 & 7 & 34 & 10.4 & 4.44 & 0.23 \\
\hline & LG6D.2 & 170.88 & 506 & 124 & 497 & 12.41 & 1.38 & 0.73 \\
\hline \multirow[t]{2}{*}{$7 \mathrm{~A}$} & LG7A.1 & 75.25 & 194 & 76 & 176 & 14.91 & 0.99 & 1.01 \\
\hline & LG7A.2 & 225.38 & 647 & 201 & 633 & 18.9 & 1.12 & 0.89 \\
\hline $7 \mathrm{~B}$ & LG7B & 170.54 & 882 & 129 & 845 & 18.19 & 1.32 & 0.76 \\
\hline \multirow[t]{2}{*}{$7 \mathrm{D}$} & LG7D.1 & 237.8 & 453 & 130 & 446 & 15.51 & 1.83 & 0.55 \\
\hline & LG7D.2 & 85.38 & 17 & 13 & 16 & 24.96 & 6.57 & 0.15 \\
\hline 1st homologous & 3 & 468.12 & 2016 & 272 & 1828 & 26.86 & 1.72 & 0.58 \\
\hline 2nd homologous & 4 & 631.98 & 1865 & 372 & 1766 & 25.44 & 1.7 & 0.59 \\
\hline 3rd homologous & 4 & 703.96 & 2846 & 524 & 2821 & 22.84 & 1.34 & 0.74 \\
\hline 4th homologous & 3 & 563.99 & 2002 & 393 & 1947 & 24.85 & 1.44 & 0.7 \\
\hline 5th homologous & 6 & 813.14 & 2947 & 621 & 2887 & 15.43 & 1.31 & 0.76 \\
\hline 6th homologous & 4 & 537.27 & 1707 & 405 & 1602 & 20.91 & 1.33 & 0.75 \\
\hline 7th homologous & 5 & 794.35 & 2193 & 549 & 2116 & 24.96 & 1.45 & 0.69 \\
\hline A genome & 10 & 1703.69 & 6215 & 1231 & 6072 & 25.68 & 1.38 & 0.72 \\
\hline$B$ genome & 8 & 1298.23 & 5860 & 1197 & 5490 & 26.86 & 1.08 & 0.92 \\
\hline D genome & 12 & 1510.87 & 3501 & 708 & 3405 & 25.44 & 2.13 & 0.47 \\
\hline TOTAL & 30 & 4512.79 & 15576 & 3136 & 14967 & 26.44 & 1.44 & 0.69 \\
\hline
\end{tabular}

\subsubsection{Effects of 1B/1R on Traits Related to Plant Height and TGW}

1RS specific marker was used to detect the population, the strains containing 1RS and 1BS were 51 and 147, respectively, and the $p$ value of the chi-square test was 8.95 $\times 10^{-12}$, which proved to be a severely segregated marker that couldn't be linked to the linkage group. According to the typing of the specific markers, the unpaired data 
T test was performed on the traits related to plant height and TGW, and there was no significant difference between 1RS and 1BS. According to the typing of specific markers, a two-factor analysis of variance was performed on the agronomic traits, and the TGW and grain width were not affected by the genotype. According to the results of the variance analysis, Duncan's new multiple range test comparison of plant height and grain length was conducted. In terms of plant height, 1 RS contributed to the reduction of plant height by $3.43 \mathrm{~cm}$. In terms of grain length, 1RS contributed to the elongation of grain by $0.11 \mathrm{~mm}$ (shown in Table S3 and Figure S3).

\subsection{QTL Mapping Analysis}

A total of 43 QTLs for PH, TGW, GL, and GW were identified by QTL mapping analysis (Table 3 and Figure S4). These QTLs with LOD values ranging from 2.51 to 53.34 were distributed on 15 chromosomes and explained $1.36-33.08 \%$ of the phenotypic variation (Table 3 and Figure S4). There were 8, 11, 15, and 9 QTLs detected for PH, TGW, GL, and GW, respectively (Table 3 and Figure S4).

Inclusive composite interval mapping (ICIM) for PH identified a total of eight QTLs, which were located on six different chromosomes (Table 3 and Figure S4): 2D(2), 4B, 4D, $5 \mathrm{~B}, 5 \mathrm{D}$, and $6 \mathrm{~B}(2)$. The QTL on $4 \mathrm{~B}$, Qph.nwafu- $4 \mathrm{~B}$, was detected in four environments. Qph.nwafu- $4 B$ was thus treated as a major QTL, which explained $9.32-13.76 \%$ of phenotypic variance with LOD values ranging from 7.93 to 26.85 . As was expected, the positive allele of Qph.nwafu-4B was contributed by Xiaoyan81 (Table 3 and Figure S4). The QTL on 4D, Qph.nwafu-4D, was detected in each of four environments. Qph.nwafu-4D was thus treated as a major QTL, which explained $20.11-27.09 \%$ of phenotypic variance with LOD values ranging from 16.78 to 42.21 . As we expected, the positive allele of Qph.nwafu- $4 D$ was contributed by Xinong1376 (Table 3 and Figure S4).

One QTL, Qph.nwafu-2D.1, for PH was detected in two environments, which explained $3.3-3.73 \%$ of phenotypic variance. The remaining QTLs were detected only in a single environment (Table 3 and Figure S4).

ICIM for TGW identified a total of eleven QTLs, which were located on eight different chromosomes (shown in Table 3 and Figure S4): 2A, 2B, 3A, 4B, 4D(2), 5A, 5D(3), and 6A. The QTL on 4B, Qtgw.nwafu-4B, was detected in three environments. Qtgw.nwafu-4B was thus treated as a stable QTL, which explained $3.43-6.85 \%$ of phenotypic variance with LOD values ranging from 2.85 to 4.37. As was expected, the positive allele of Qtgw.nwafu- $4 B$ was contributed by Xinong1376 (shown in Table 3 and Figure S4). Based on the initial QTL mapping results, we developed two KASP markers, KASP_AX-109316968 and KASP_AX109333198 , and integrated them into the genetic map. When remapping with this integrated KASP marker, it was indicated that Qtgw.nwafu- $4 B$ was located in a $5 \mathrm{cM}$ interval on chromosome arm 4BS, between the markers of AX-111494900 and AX-94438527, containing the newly developed KASP markers, including KASP_AX-109316968 and KASP_AX109333198 (Figure S5 and Table S3).Three QTLs, Qtgw.nwafu-4D.1, Qtgw.nwafu-5A, and Qtgw.nwafu-5D.1, for TGW were detected in each of two environments, which explained $2.85-14.79 \%$ of phenotypic variance. The remaining QTLs were detected only in a single environment (Table 3). 
Table 3. Full genomic QTL mapping results of plant height and grain related traits in the F8 RIL lines between Xinong1376 and Xiaoyan81.

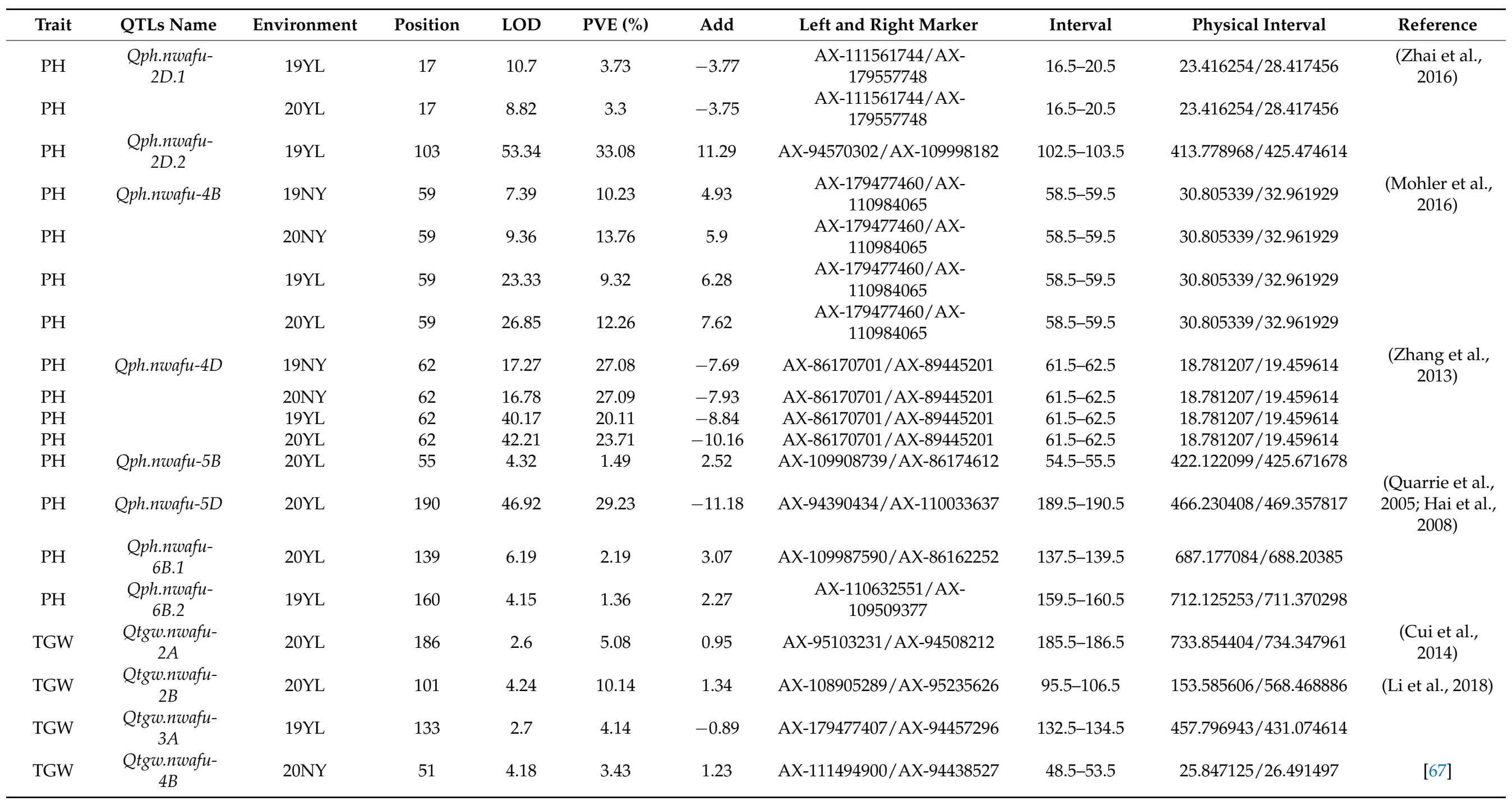


Table 3. Cont.

\begin{tabular}{|c|c|c|c|c|c|c|c|c|c|c|}
\hline Trait & QTLs Name & Environment & Position & LOD & PVE (\%) & Add & Left and Right Marker & Interval & Physical Interval & Reference \\
\hline TGW & & 19YL & 51 & 4.37 & 6.85 & 1.18 & AX-111494900/AX-94438527 & $49.5-53.5$ & $25.847125 / 26.491497$ & \multirow{4}{*}{$\begin{array}{l}\text { (Mohler et al., } \\
\text { 2016) }\end{array}$} \\
\hline TGW & & $19 N Y$ & 52 & 2.85 & 5.02 & 1.06 & AX-94438527/AX-110383634 & $48.5-55.5$ & $26.491497 / 28.71668$ & \\
\hline TGW & $\begin{array}{l}\text { Qtgw.nwafu- } \\
\text { 4D.1 }\end{array}$ & $19 N Y$ & 60 & 5.87 & 9.73 & -1.44 & AX-89703298/AX-86170701 & $56.5-60.5$ & $16.926631 / 18.781207$ & \\
\hline TGW & & $20 N Y$ & 60 & 6.2 & 5.25 & -1.48 & AX-89703298/AX-86170701 & $56.5-60.5$ & $16.926631 / 18.781207$ & \\
\hline TGW & $\begin{array}{l}\text { Qtgw.nwafu- } \\
4 D .2\end{array}$ & 19YL & 111 & 3.54 & 5.55 & -1.03 & AX-111926032/AX-94818797 & $107.5-112.5$ & $476.884228 / 477.371597$ & \multirow{16}{*}{$\begin{array}{l}\text { (Cui et al., } \\
\text { 2014) } \\
\text { (Mir et al., } \\
\text { 2012) }\end{array}$} \\
\hline TGW & $\begin{array}{l}\text { Qtgw.nwafu- } \\
5 A\end{array}$ & 19YL & 44 & 7.18 & 11.94 & 1.51 & AX-95510385/AX-95117188 & $43.5-45.5$ & $698.508129 / 702.466804$ & \\
\hline TGW & \multirow{3}{*}{$\begin{array}{l}\text { Qtgw.nwafu- } \\
\text { 5D.1 }\end{array}$} & $20 Y L$ & 44 & 3.51 & 6.99 & 1.11 & AX-95510385/AX-95117188 & $43.5-45.5$ & $698.508129 / 702.466804$ & \\
\hline TGW & & $19 N Y$ & 37 & 5.51 & 9.32 & 1.4 & $\begin{array}{c}\text { AX-111543112/AX- } \\
110576074\end{array}$ & $34.5-38.5$ & $38.070293 / 41.294446$ & \\
\hline TGW & & $20 N Y$ & 37 & 14.79 & 14.24 & 2.43 & $\begin{array}{l}\text { AX-111543112/AX- } \\
110576074\end{array}$ & $35.5-38.5$ & $38.070293 / 41.294446$ & \\
\hline TGW & $\begin{array}{l}\text { Qtgw.nwafu- } \\
\text { 5D.2 }\end{array}$ & $20 N Y$ & 46 & 6.46 & 5.56 & -1.51 & $\begin{array}{l}\text { AX-111019963/AX- } \\
110085499\end{array}$ & $44.5-49.5$ & $42.928674 / 44.192407$ & \\
\hline TGW & $\begin{array}{l}\text { Qtgw.nwafu- } \\
\quad 5 D .3\end{array}$ & 19YL & 81 & 3.66 & 5.83 & 1.05 & $\begin{array}{l}\text { AX-110867187/AX- } \\
108827297\end{array}$ & $79.5-81.5$ & $369.202139 / 370.064947$ & \\
\hline GL & Qgl.nwafu-1A & 19YL & 150 & 3.3 & 3.11 & -0.06 & AX-95682344/AX-108726119 & $148.5-150.5$ & $572.350803 / 572.658176$ & \\
\hline GL & $\begin{array}{l}\text { Qgl.nwafu- } \\
\quad 1 B .1\end{array}$ & $20 \mathrm{YL}$ & 0 & 3.62 & 4.51 & 0.09 & AX-94835306/AX-179476279 & $0-0.5$ & $59.471177 / 94.978091$ & \\
\hline GL & $\begin{array}{l}\text { Qgl.nwafu- } \\
1 B .2\end{array}$ & $19 \mathrm{NY}$ & 65 & 3.51 & 4.49 & 0.08 & AX-94650293/AX-112288501 & $64.5-66.5$ & $640.845515 / 641.632325$ & \\
\hline GL & \multirow{3}{*}{ Qgl.nwafu-3A } & 19YL & 65 & 5.23 & 5.14 & 0.08 & AX-94650293/AX-112288501 & $64.5-65.5$ & $640.845515 / 641.632325$ & \\
\hline GL & & $20 Y L$ & 135 & 5.71 & 7.61 & -0.1 & AX-94426283/AX-110122062 & $134.5-136.5$ & $511.755031 / 510.853056$ & \\
\hline GL & & $20 N Y$ & 137 & 3.78 & 6.88 & -0.09 & AX-179557644/AX-94387510 & $136.5-137.5$ & $541.482465 / 540.048345$ & \\
\hline GL & Qgl.nwafu- $4 A$ & $20 N Y$ & 49 & 4.41 & 9.11 & 0.1 & $\begin{array}{l}\text { AX-111251110/AX- } \\
179476673\end{array}$ & $46.5-53.5$ & $407.389107 / 129.089816$ & \\
\hline GL & & $19 \mathrm{NY}$ & 50 & 4.57 & 6.07 & 0.1 & $\begin{array}{c}\text { AX-111251110/AX- } \\
179476673\end{array}$ & $47.5-52.5$ & $407.389107 / 129.089816$ & \\
\hline GL & $\begin{array}{l}\text { Qgl.nwafu- } \\
\quad 4 B .1\end{array}$ & 19YL & 51 & 4.28 & 4.17 & 0.07 & $\begin{array}{c}\text { AX-179476673/AX- } \\
110173140\end{array}$ & $47.5-52.5$ & $129.089816 / 140.310606$ & \\
\hline
\end{tabular}


Table 3. Cont.

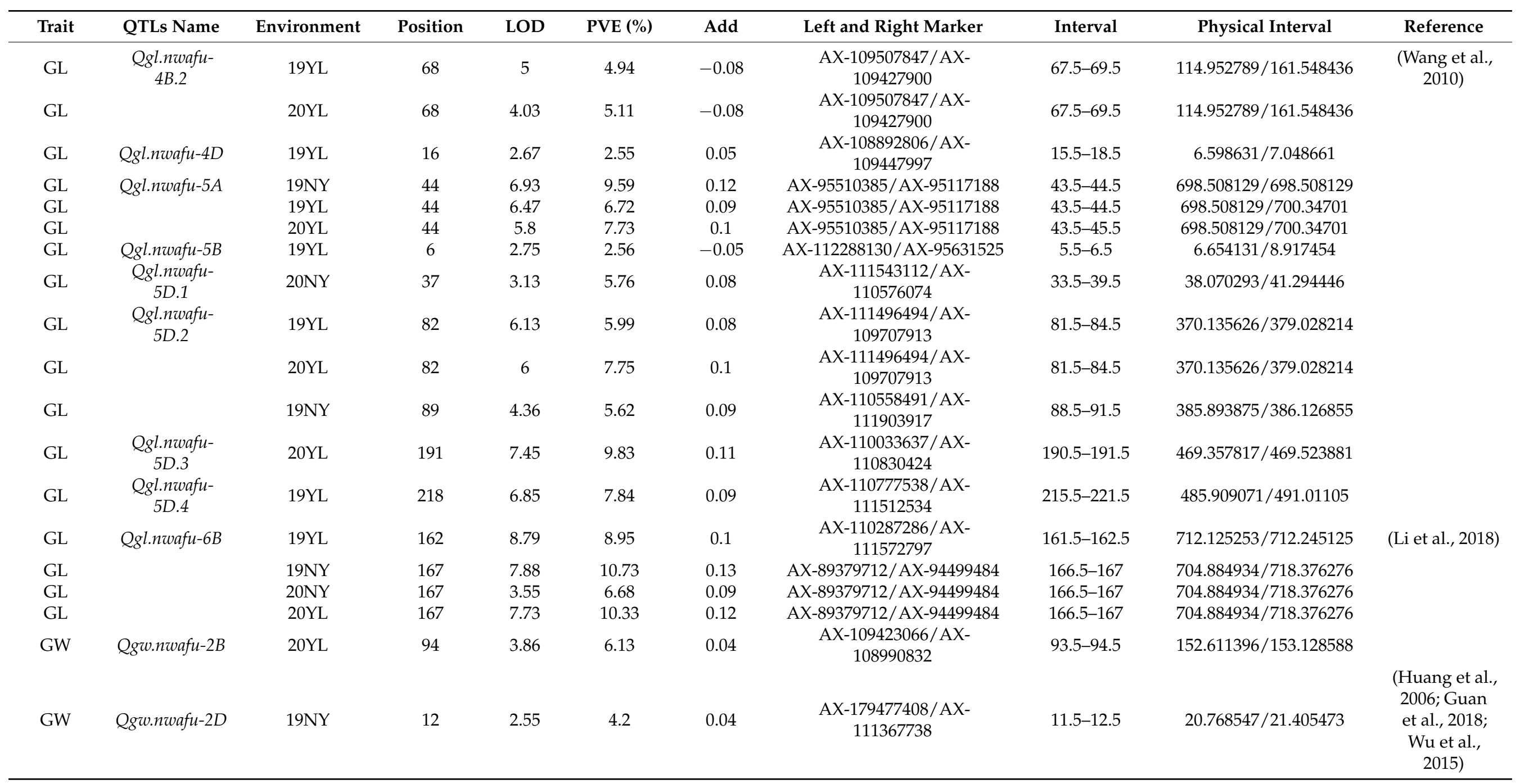


Table 3. Cont.

\begin{tabular}{|c|c|c|c|c|c|c|c|c|c|c|}
\hline Trait & QTLs Name & Environment & Position & LOD & PVE (\%) & Add & Left and Right Marker & Interval & Physical Interval & Reference \\
\hline GW & Qgw.nwafu-3A & 19YL & 311 & 3.18 & 4.66 & 0.04 & $\begin{array}{l}\text { AX-110915909/AX- } \\
110475339\end{array}$ & $308.5-311$ & $746.360221 / 749.849798$ & $\begin{array}{l}\text { (Lee et al., } \\
\text { 2014) }\end{array}$ \\
\hline GW & $\begin{array}{l}\text { Qgw.nwafu- } \\
\quad 4 B .1\end{array}$ & $19 N Y$ & 51 & 4.15 & 6.95 & 0.05 & AX-111494900/AX-94438527 & $49.5-54.5$ & $25.847125 / 26.491497$ & \\
\hline GW & & $20 \mathrm{NY}$ & 51 & 3.5 & 6.85 & 0.05 & AX-111494900/AX-94438527 & $48.5-54.5$ & $25.847125 / 26.491497$ & \\
\hline GW & $\begin{array}{l}\text { Qgw.nwafu- } \\
4 B .2\end{array}$ & 20YL & 68 & 3.91 & 6.23 & 0.04 & $\begin{array}{c}\text { AX-109507847/AX- } \\
109427900\end{array}$ & $67.5-68.5$ & $114.952789 / 161.548436$ & $\begin{array}{c}\text { (Wang et al., } \\
\text { 2010) }\end{array}$ \\
\hline GW & $\begin{array}{l}\text { Qgw.nwafu- } \\
4 B .3\end{array}$ & 19YL & 77 & 9.23 & 15.24 & 0.07 & AX-179559104/AX-95658798 & $76.5-77.5$ & $520.214474 / 523.447693$ & \\
\hline GW & Qgw.nwafu-4D & $20 N Y$ & 60 & 3.2 & 6.32 & -0.05 & AX-89703298/AX-86170701 & $59.5-61.5$ & $16.926631 / 18.781207$ & \\
\hline GW & & $19 N Y$ & 61 & 4.15 & 7.22 & -0.05 & AX-86170701/AX-110572006 & $59.5-61.5$ & $18.781207 / 19.179341$ & \\
\hline GW & & 19YL & 63 & 7.93 & 12.12 & -0.06 & AX-86170701/AX-89445201 & $61.5-64.5$ & $18.781207 / 19.459614$ & \\
\hline GW & & $20 Y L$ & 63 & 6.37 & 10.37 & -0.05 & AX-86170701/AX-89445201 & $61.5-63.5$ & $18.781207 / 19.459614$ & \\
\hline GW & Qgw.nwafu-5D & $19 N Y$ & 163 & 3.5 & 6.01 & 0.04 & $\begin{array}{c}\text { AX-109317498/AX- } \\
109855976\end{array}$ & $159.5-166.5$ & $448.686533 / 449.292436$ & \\
\hline GW & Qgw.nwafu-6D & $20 N Y$ & 4 & 2.51 & 5.8 & 0.05 & $\begin{array}{c}\text { AX-111594857/AX- } \\
109406081\end{array}$ & $0-12.5$ & $12.650045 / 8.255713$ & \\
\hline
\end{tabular}

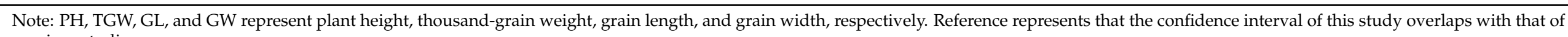
previous studies. 
ICIM for GL identified a total of fifteen QTLs, which were located on ten different chromosomes (Table 3 and Figure S4): $1 \mathrm{~A}, 1 \mathrm{~B}(2), 3 \mathrm{~A}, 4 \mathrm{~A}, 4 \mathrm{~B}(2), 4 \mathrm{D}, 5 \mathrm{~A}, 5 \mathrm{~B}, 5 \mathrm{D}(4)$ ) and $6 \mathrm{~B}$. The QTL on 6B, Qgl.nwafu-6B, was detected in four environments. Qgl.nwafu-6B was thus treated as a major QTL, which explained $6.68-10.73 \%$ of phenotypic variance with LOD values ranging from 3.35 to 8.79. As was expected, the positive allele of Qgl.nwafu-6B was contributed by Xinong1376 (Table 3). The QTL on 5A, Qgl.nwafu-5A, was detected in in three environments. Qgl.nwafu-5A was thus treated as a stable QTL, which explained 6.72$9.59 \%$ of phenotypic variance with LOD values ranging from 5.8 to 6.93 . As we expected, the positive allele of Qgl.nwafu-5A was contributed by Xinong1376 (Table 3 and Figure S4). The QTL on 5D, Qgl.nwafu-5D.2, was detected in three environments. Qgl.nwafu-5D.2 was thus treated as a stable QTL, which explained $5.62-7.75 \%$ of phenotypic variance with LOD values ranging from 4.36 to 6.13. As was expected, the positive allele of Qgl.nwafu5D.2 was contributed by Xinong1376 (Table 3 and Figure S4). Four QTLs, Qgl.nwafu-1B.2, Qgl.nwafu-3A, Qgl.nwafu-4A, and Qgl.nwafu-4B.2, for GL were detected in two environments, explaining $3.51-6.13 \%$ of phenotypic variance. The remaining QTLs were detected only in a single environment (Table 3 and Figure S4).

ICIM for GW identified a total of nine QTLs, which were located on seven different chromosomes (Table 3, Figure S4): 2B, 2D, 3A, 4B(3), 4D, 5D, and 6D. The QTL on 4D, Qgw.nwafu-4D, was detected in each of the four environments. Qgw.nwafu- $4 D$ was thus treated as a major QTL, which explained $6.32-12.12 \%$ of phenotypic variance with LOD values ranging from 3.2 to 7.93. As we expected, the positive allele of $Q g w$.nwafu- $4 D$ was contributed by Xinong1376 (Table 3). One QTL, Qgw.nwafu-4B.1, for GW was detected in two environments, which explained $6.85-6.95 \%$ of phenotypic variance. The remaining QTLs were detected only in a single environment (shown in Table 3 and Figure S4).

Two QTL clusters were identified on chromosomes 4B and 4D (Table 3 and Figure S4). For the QTL cluster on chromosome 4B, Qtgw.nwafu- $4 B$ for TGW was co-localized with Qgl.nwafu-4B.1 for GL, and Qph.nwafu-4B and Qgl.nwafu-4B.2 for GL were co-localized with Qgl.nwafu-4B.2 and Qgl.nwafu-4B.3 for GL in a region ranging from $51 \mathrm{cM}$ to $77 \mathrm{cM}$. On chromosome 4D, Qph.nwafu-4D for PH was clustered with Qtgw.nwafu-4D.1 for TGW, and Qgw.nwafu-4D for GW was clustered with with the alleles from Xiaoyan81 increasing PH, TGW and GW.

\section{Discussion}

\subsection{The Impact of Linkage Map on QTL Mapping}

In this research, a linkage map, based on $50 \mathrm{~K}$ microarray markers, was constructed from $198 \mathrm{~F}_{8}$ RIL lines derived from the combination of two parents, Xinong1376 and Xiaoyan81. The linkage map had a total length of $4512.79 \mathrm{cM}$, covering 21 chromosomes of wheat. The reason why no marks could be targeted in the regions of more than $200 \mathrm{MB}$ in the middle of the four chromosomes 1D, 5A, and 6A was that a recombination-barren area near the centromere appeared in the above regions, as was shown in Figure 1. Both parents were derived from the backbone parent Xiaoyan6, and a region with the same haplotype was formed rapidly [68], so that the two parents had no markers with polymorphic differences in the above regions. There was a long, excellent haplotype segment on chromosome 6 A $[60,69]$. 

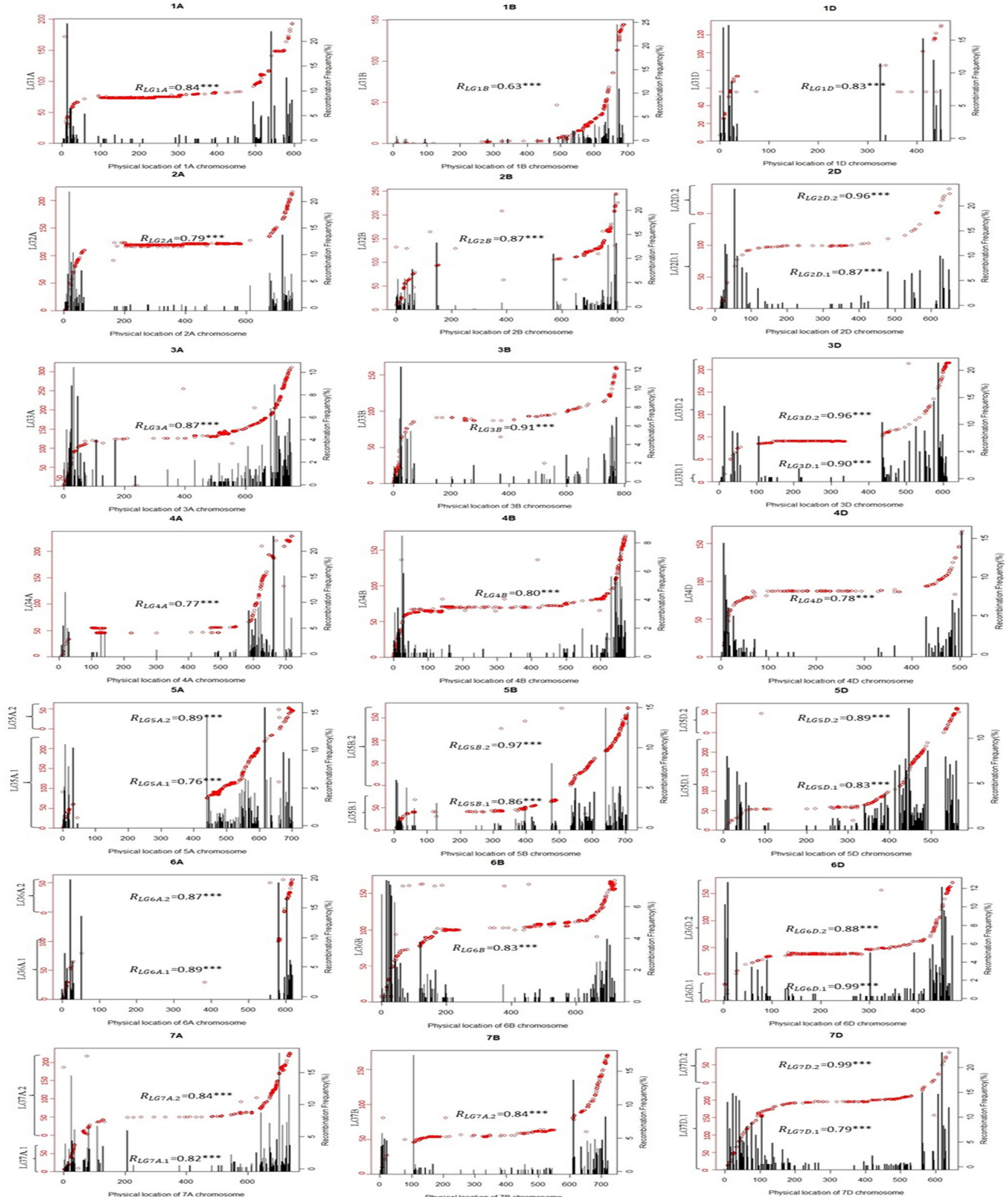

Figure 1. Collinearity analysis of genetic map and reference genome. NOTE: The genetic distances of the linkage group are shown as the left Y-axis, the recombination rate of bin markers as the right Y-axis, the physical location of the markers as the $x$-axis, the collinearity as the red scatter dots, and the recombination rate of bin markers on the reference genome as the black histogram. A, B, D are the three subgroups of common wheat. 
In this study, 43 QTLs were located. The genetic distance confidence interval was 0.5-12.5 cM, and the physical distance of the markers on both sides was $0.0201 \mathrm{MB}$ 414.88328 MB. As was shown in Table 2, the genetic distance confidence interval was not proportional to the physical distance, which reflected the imbalance of the recombination exchange on the chromosomes.

By combining Figure S4 and Figure 1, it appeared that there were 5 QTLs located in the recombination-barren region of the reference genome, and more than 20 MB QTLs were distributed in this candidate region. The linkage interval of Qgl.nwafu-1B.1 was 0-0.5 cM, while the physical interval was 59.47117 MB-94.978091 MB and the interval physical distance was $35.506914 \mathrm{MB}$. The reason was that Xinong1376 belonged to the 1BL/1RS translocation line, and there was almost no recombination or recombination disorder between 1 RS and 1BS $[6,38,70,71]$. Although the genetic distance of the confidence interval was short, the corresponding physical distance of it was far. As was shown in Figure S4, the linkage region of Qtgw.nwafu-2B was $95.5 \mathrm{cM}-106.5 \mathrm{cM}$, and no marks could be targeted in this region. This area belongs to the reorganization cold spot area, and the corresponding physical distance was 153.585606 MB-568.468886 MB. The linkage regions of Qtgw/gl.nwafu-3A, Qgl.nwafu-4A, and Qgw.nwafu-4B.2 were 132.5 cM-134.5 cM, 46.5 cM$53.5 \mathrm{cM}$, and $67.5 \mathrm{cM}-69.5 \mathrm{cM}$, respectively, and the corresponding regions were 457.796943 MB-431.074614 MB, 407.389107 MB-129.089816 MB, and 114.952789 MB-161.548436 MB, respectively. As was shown in Table 2, the above three QTLs all fell in the recombinationbarren region of linkage groups with a large physical interval. The confidence interval of Qgw.nwafu-6D, which was the largest, was $0 \mathrm{cM}-12.5 \mathrm{cM}$, but the corresponding physical region was $12.650045 \mathrm{MB}-8.255713 \mathrm{MB}$, and the interval was only 4.4 MB. Qgw.nwafu-6D was located at the top of the chromosome, and belonged to the recombination-rich region, with a big genetic distance but a short corresponding physical distance.

\subsection{Comparison with Previous Research Results}

Two loci as environment-stable QTLs, targeted in three or four kinds of environments, were Qph.nwafu-4B and Qph.nwafu-4D, which control plant height. In the confidence interval, the function markers including $R h t-1$ and $R h t-2$ were AX-179477460 and AX86170701, respectively. According to the additive effect, the effect of the Qph.nwafu-4D mutant in lowering plant height was stronger than that of the Qph.nwafu- $4 B$ mutant, which was consistent with the results of Zhai et al. [6] The locus, Qgl.nwafu-5A, which controlled the grain length, corresponded to the physical location of 698.508129 MB-700.34701 MB, which was located at the end of the chromosome. Compared with the results of previous studies [23,29-42], Qgl.nwafu-5A was a new QTL. The location of Qgl.nwafu-5D.2 which controlled the length of the grain corresponded to the physical location of $370.135626 \mathrm{MB}-$ 386.126855 MB. Based on previous research [22,24,35,42,43], Qgl.nwafu-5D.2 was defined as a new QTL as well. The location of Qgl.nwafu-6B, which controls grain length, corresponded to the physical location of 704.884934 MB-718.376276 MB. Compared with the results of previous studies [35], the physical location marked by IWB2746 was 701.387367 MB. As was shown in Figure S4, the collinearity between the linkage group and the physical position was relatively disordered at the end of chromosome 6B, and it was not clear whether they were the same QTL.

Qph.nwafu-4B (controlling plant height) and Qtgw.nwafu-4B (controlling TGW) had an obvious linkage relationship, with a distance of 7-8 cM. The physical location corresponding to this location of Qph.nwafu-4B was $30.805339 \mathrm{MB}-32.961929 \mathrm{MB}$, and the physical position corresponding to the location of Qtgw.nwafu-4B was 25.847125 MB-26.491497 MB. Guan's QTL mapping results were marked as BS00084904_51 and BS00011338_51 on both sides, and the physical location was 28.954526 MB-66.811785 MB [30]. Cui Fa's QTL mapping results were marked as Rht-B1 and Xmag2055 on both sides, and the physical location was 30.860778 MB-20.741542 MB [70]. Quarrie's QTL mapping results were marked as Rht-B1 and gwm165.1 on both sides, and the physical location was 30.860778 MB-269.948831 MB [42] (The results of previous studies on chromosome 4B and the specific 
QTL information related to TGW are shown and illustrated in Table S4). From the QTL mapping results in this study and the above three research results, it was suggested that the confidence interval had this overlap while the confidence interval of this study was the shortest. Based on heredity Doumai/Shi 41875, Li mapped the plant height and TGW. The physical location on chromosome 4B was 46.621203 MB [35], which was not the same QTL. The confidence intervals of Qph.nwafu-4D, Qtgw.nwafu-4D.1, and Qgw.nwafu-4D had clear overlaps and were stably expressed in multiple environments. The mutant at this locus lowered plant height while also decreasing TGW and grain width. Rht2 had a significant effect on TGW, as previously shown by Mohler et al. [32]. There was a significant overlap in the confidence interval of Qph.nwafu-5D controlling plant height and Qgl.nwafu-5D.3 controlling grain length, with a typical pleiotropism. This locus's physical position was 466.230408 MB-469.357817 MB, and its additive effect was opposite, so physiological antagonism occurred. The location of wmc215 targeted by Hai et al. was $472.369175 \mathrm{MB}$, and that of gwm 212 targeted by Quarrie was $472.630187 \mathrm{MB}$, which was in line with previous localization results $[42,43]$. The difference in physical location was $3 \mathrm{MB}$. Since subgroup D had a large linkage disequilibrium [72], it was impossible to determine whether these loci were the same one. Qtgw.nwafu-5D.1 controlling TGW and Qgl.nwafu-5D.1 controlling grain length were located in the region from 38.070293 MB-41.294446 MB, neither of which belonged to the same region of the $5 \mathrm{D}$ chromosome, compared with the results of previous studies $[35,42,43,73]$.

\subsection{Qtgw.Nwafu-4B Molecular Marker Development}

Based on the confidence interval of the parental 660K chip marker, two co-segregating KASP markers were developed. Two KASP molecular markers were inserted into the original genetic map, and the genetic map of chromosome $4 \mathrm{~B}$ maintained a high degree of collinearity. Two KASP molecular markers were inserted into the original genetic map, and the genetic map of chromosome $4 \mathrm{~B}$ maintained a high degree of collinearity. The primer sequences and typing information of the two molecular markers of KASP_AX-109316968 and KASP_AX-109333198 are shown in Figure S5 and Table S5. Qph.nwafu-4B (controlling plant height) and Qtgw.nwafu-4B (controlling TGW) had an obvious linkage relationship, with a distance of 7-8 cM. Breeding is based on molecular markers that control plant height and thousand-grain weight to select strains with low plant height and large grain weight.

\section{Materials and Methods}

\subsection{Plant Materials, Experimental Design, and Investigation of Agronomic Traits}

Xinong 1376 is the female parent and Xiaoyan 81 is the male parent. Based on the single-grain transmission method, 198 RIL lines were generated. There were planted in Yangling, Shaanxi province and Nanyang, Henan province, from October 2018 to June 2019 and from October 2019 to June 2020, respectively. A randomized block design (repeated five times, with two rows of districts, $2 \mathrm{~m}$ row length, 70 plants per row, and $0.3 \mathrm{~m}$ row spacing) was adopted in each experimental site. The other field managements were subject to the same treatment as the local. During the wax maturity period of wheat, five individual plants were sampled in sequence from the fifth plant of each family. Plant height, TGW, grain length and grain width were also measured. By R/lme4 [73], each environment's agronomic traits were obtained for $\mathrm{W}$-test, and then multiple comparisons of parental traits and calculation of heritability were completed. The heritability of the two traits was calculated by using the formula as follows:

$$
H^{2}=\mathrm{V}_{\mathrm{G}} /\left(\mathrm{V}_{\mathrm{G}}+\mathrm{V}_{\mathrm{GY}} / \mathrm{y}+\mathrm{V}_{\mathrm{GE}} / \mathrm{e}+\mathrm{V}_{\mathrm{E}} / \mathrm{nr}\right) \times 100 \%
$$

where $\mathrm{y}$ is the number of years, $\mathrm{e}$ is the number of environments, and $\mathrm{n}$ is the number of repetitions.

The pedigrees of Xinong1376 and Xiaoyan81 are illustrated in Figure S2. 


\subsection{Construction and Evaluation of Genetic Maps}

The wheat genomic DNA, with tender wheat leaves as the plant material, was extracted by CTAB, and the quality and quantity of DNA were detected and confirmed. Meanwhile, the DNA of each line was hybridized on the wheat 50K SNP array containing 66,832 markers using Burdock Biotechnology (Beijing, China).

The course of constructing the map was conducted as follows: The BIN function of IciMapping 4.1 [70] was utilized to analyze the markers, and the markers with partial separation rate $(p<0.001)$ and missing rate $(>15 \%)$ were removed. The Kosambi function with LOD $\geq 5$ was applied to group the combined marker groups in JoinMap 4.0; Kosambi mapping of MSTmap [74], according to the clustering results, was used in the markers' ordination. The flanking sequences of SNPs were BLAST aligned with the genome of IWGSC RefSeq v1.0 (http:/ / www.wheatgenome.org/News / Latest-news / All-IWGSC-data-related-tothe-reference-sequence-of-bread-wheat-IWGSC-RefSeq-v1.0-publicly-available-at-URGI) to obtain their physical locations. The version of BLAST used was 2.2.31 -outfmt 3num_alignments 5 .

\subsection{Identification of $1 B L / 1 R S$ Translocation}

1RS, applied to identify parents and populations as $x$-sec-p1/x-sec-p2, respectively, was a specific marker [75]. Xinong1376 was identified as a 1BS/1RS translocation line. 1B/1R genotyping and traits data were stored in Table S4 and Figure S3. Analysis of variance and Duncan's new multiple range test comparisons based on genotype and trait were conducted.

\subsection{Detection of Quantitative Loci}

IciMapping 4.2 based on the biparental population (BIP) module with the inclusive composite interval mapping (ICIM, http://www.isbreeding.net/software/?type= detail\&id=28) was used for QTL mapping on data obtained from different environments. QTL mapping of the phenotypic values in the four environments was carried out. The LOD value was determined in 1000 permutation tests with a $=0.05$ (Type I Error) as the parameter, and the background was set and controlled by the positive and negative stepwise regression, with the step width set to 1cM. QTLs were named based on the International Rules of Genetic Nomenclature (http:/ / whea.pw.usda.gov/ggpages/ wgc/98/Intro.htm). Mapchart2.3 (https:/ / www.wur.nl/en/Research-Results/ResearchInstitutes/plant-research/Biometris-1/SoftwareService/Download-MapChart.htm) was used for the drawing of the genetic and QTL mapping. The collinearity drawing of genetic and physical maps, and the calculation of correlation coefficient were conducted by package plotrix (https://cran.r-project.org/src/contrib/Archive/plotrix/) and package (https://github.com/braverock/PerformanceAnalytics) of R software.

\subsection{Breeding Molecular Marker Development}

After obtaining the preliminary QTL mapping results, we anchored the flanking markers to the physical map. In order to develop a competitive allele-specific PCR (KASP) marker that can be used to track stable TGW QTLs, we used the Wheat660K SNP array to further genotype the parents of the Xinong1376/Xiaoyan81 population [63,71]. According to the method of Ma et al. [63], SNPs located in the main QTL interval were selected to develop KASP markers. The developed integrated genetic map of KASP markers was applied to relocate the target QTL.

\section{Conclusions}

In this research, a genetic map covering the entire wheat genome was constructed, with a total of 3136 bin markers, including 15576 SNP markers, and the total length of the linkage map was $4512.79 \mathrm{cM}$. Except for chromosome 1B, the ends of chromosomes were identified as recombination-rich areas, while the middle areas were recombination-barren. Both the genetic map and the physical map showed a significant correlation when $p=0.001$. 
The correlation coefficient ranged from 0.63 to 0.99 . There was almost no recombination between 1RS and 1BS. Among 43 QTLs indirectly compared by reference genome, only 13 QTLs were consistent with previous mapping results, and 30 QTLs were defined as new QTLs. Seven environment-stable QTLs were detected in this population, including Qph.nwafu-4B, Qtgw.nwafu-4B, Qgw.nwafu-4D, Qph.nwafu-4D, Qgl.nwafu-5A, Qgl.nwafu-5D.2, and Qgl.nwafu-6B. Qtgw.nwafu-4B, which influenced TGW, showed an explanation rate of $3.43-6.85 \%$ for phenotypic variation, with two co-segregating KASP markers developed, and the physical locations corresponding to KASP_AX-109316968 and KASP_AX-109519968 were 25.888344 MB and 25.847691 MB, respectively, for details, see Figure 2. Qph.nwafu-4B (controlling plant height) and Qtgw.nwafu-4B (controlling TGW) had an obvious linkage relationship, with a distance of $7-8 \mathrm{cM}$. The physical location corresponding to this location of Qph.nwafu- $4 B$ was 30.805339 MB-32.961929 MB, and the physical position corresponding to this location of $Q \operatorname{tgw} . n w a f u-4 B$ was $25.847125 \mathrm{MB}-26.491497 \mathrm{MB}$. There is a functional marker (AX-179477460) for the control value of plant height in the Qph.nwafu- $4 B$ confidence interval, and this locus can be determined to be Rht-B1. The physical locations of Qph.nwafu$4 B$, Qph.nwafu- $4 D$, and $Q g w . n w a f u-4 D$ were consistent with previous mapping results. For Qgl.nwafu-6B, it couldn't be accurately determined whether it was a new QTL or not. Two QTL clusters were identified on chromosomes 4B and 4D (Table 3 and Figure S4). 


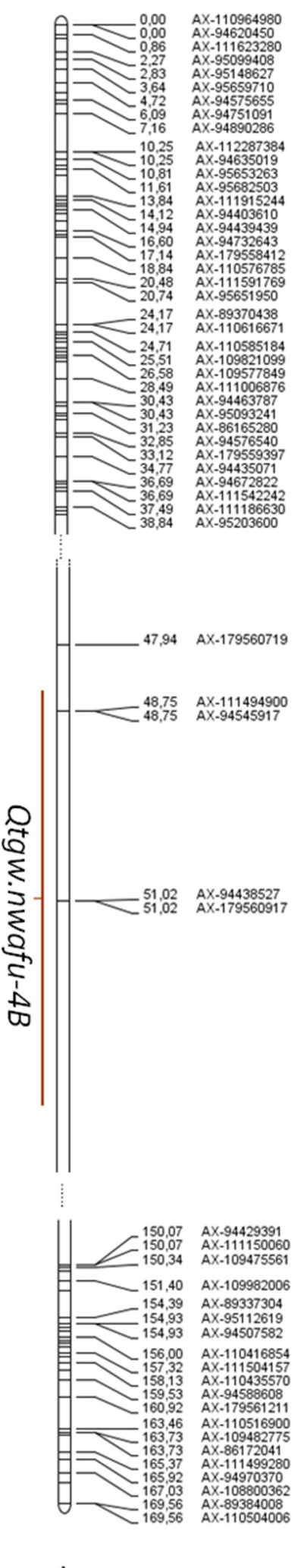

A

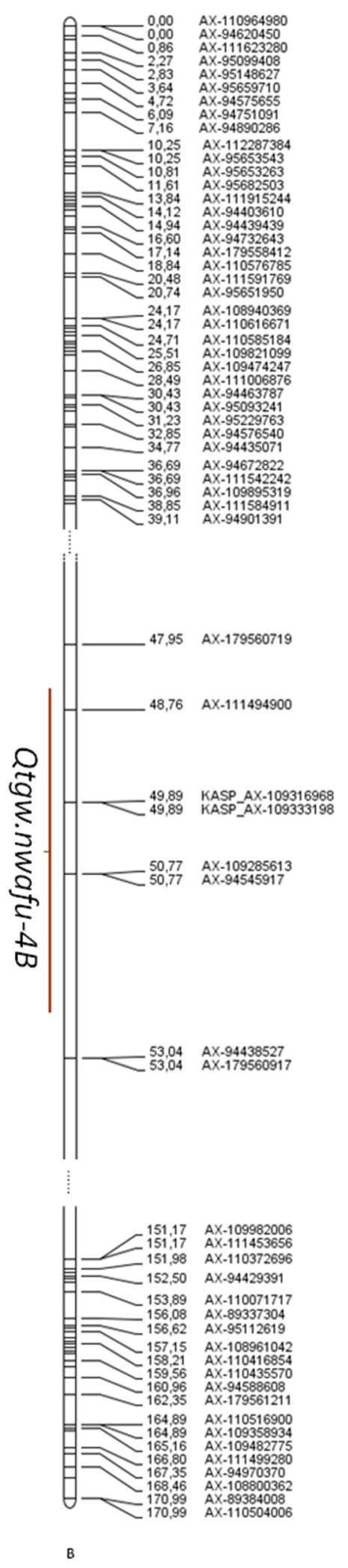

Figure 2. The linkage group corresponding to chromosome 4B. Note: (A) represents the original linkage group, and (B) the linkage group after the addition of the KASP marker.

Supplementary Materials: The following are available online at https: / www.mdpi.com/article/ 10.3390 / plants10061167/s1, Table S1. Statistical analysis of parent and RIL lines for traits, Table S2. Single-nucleotide polymorphism (SNP) marker statistics about distribution and density on 21 wheat chromosomes derived from crossing between Xinong1376 and Xiaoyan81, Table S3. Full genomic 
QTL mapping results of plant height and grain related traits in the F8 RIL lines between Xinong1376 and Xiaoyan81, Figure S1. Collinearity analysis of genetic map and reference genome, Figure S2. The linkage group corresponding to chromosome $4 \mathrm{~B}$.

Author Contributions: D.S., D.H. and J.W. designed the research. C.Z. and D.L. conducted genotyping of the population. C.Z., D.L., R.Y., J.Y., X.S., J.J., P.S. and Z.Z. conducted phenotyping of the population. C.Z. analyzed all data. D.L. wrote the paper. All authors have read and agreed to the published version of the manuscript.

Funding: This research was funded by grants from the National Key Research and Development Program of China (2016YFD0101802).

Institutional Review Board Statement: Not applicable.

Informed Consent Statement: Not applicable.

Data Availability Statement: Please refer to suggested Data Availability Statements in section "MDPI Research Data Policies" at https://www.mdpi.com/ethics.

Conflicts of Interest: This study did not have any conflict of interest.

\section{References}

1. Bailey-Serres, J.; Parker, J.E.; Ainsworth, E.A.; Oldroyd, G.E.D.; Schroeder, J.I. Genetic strategies for improving crop yields. Nature 2019, 575, 109-118. [CrossRef]

2. Hanif, M.; Gao, F.; Liu, J.; Wen, W.; Zhang, Y.; Rasheed, A.; Xia, X.; He, Z.; Cao, S. TaTGW6-A1, an ortholog of rice TGW6, is associated with grain weight and yield in bread wheat. Mol. Breed. 2016, 36, 1. [CrossRef]

3. Kumari, S.; Jaiswal, V.; Mishra, V.K.; Paliwal, R.; Balyan, H.S.; Gupta, P.K. QTL mapping for some grain traits in bread wheat (Triticum aestivum L.). Physiol. Mol. Biol. Plants 2018, 24, 909-920. [CrossRef]

4. Xie, Q.; Mayes, S.; Sparkes, D.L. Carpel size, grain filling, and morphology determine individual grain weight in wheat. J. Exp. Bot. 2015, 66, 6715-6730. [CrossRef]

5. Guan, P.; Di, N.; Mu, Q.; Shen, X.; Wang, Y.; Wang, X.; Yu, K.; Song, W.; Chen, Y.; Xin, M.; et al. Use of near-isogenic lines to precisely map and validate a major QTL for grain weight on chromosome $4 \mathrm{AL}$ in bread wheat (Triticum aestivum L.). Theor. Appl. Genet. 2019, 132, 2367-2379. [CrossRef]

6. Zhai, H.; Feng, Z.; Li, J.; Liu, X.; Xiao, S.; Ni, Z.; Sun, Q. QTL Analysis of Spike Morphological Traits and Plant Height in Winter Wheat (Triticum aestivum L.) Using a High-Density SNP and SSR-Based Linkage Map. Front. Plant Sci. 2016, 7, 1617. [CrossRef]

7. Jiang, Q.; Hou, J.; Hao, C.; Wang, L.; Ge, H.; Dong, Y.; Zhang, X. The wheat (T. aestivum) sucrose synthase 2 gene (TaSus2) active in endosperm development is associated with yield traits. Funct. Integr. Genom. 2011, 11, 49-61. [CrossRef]

8. Hou, J.; Jiang, Q.; Hao, C.; Wang, Y.; Zhang, H.; Zhang, X. Global selection on sucrose synthase haplotypes during a century of wheat breeding. Plant Physiol. 2014, 164, 1918-1929. [CrossRef]

9. Su, Z.; Hao, C.; Wang, L.; Dong, Y.; Zhang, X. Identification and development of a functional marker of TaGW2 associated with grain weight in bread wheat (Triticum aestivum L.). Theor. Appl. Genet. 2011, 122, 211-223. [CrossRef]

10. Yang, Z.; Bai, Z.; Li, X.; Wang, P.; Wu, Q.; Yang, L.; Li, L.; Li, X. SNP identification and allelic-specific PCR markers development for TaGW2, a gene linked to wheat kernel weight. Theor. Appl. Genet. 2012, 125, 1057-1068. [CrossRef]

11. Ma, L.; Li, T.; Hao, C.; Wang, Y.; Chen, X.; Zhang, X. TaGS5-3A, a grain size gene selected during wheat improvement for larger kernel and yield. Plant Biotechnol. J. 2016, 14, 1269-1280. [CrossRef]

12. Ma, D.; Yan, J.; He, Z.; Wu, L.; Xia, X. Characterization of a cell wall invertase gene TaCwi-A1 on common wheat chromosome 2A and development of functional markers. Mol. Breed. 2010, 29, 43-52. [CrossRef]

13. Zhang, L.; Zhao, Y.L.; Gao, L.F.; Zhao, G.Y.; Zhou, R.H.; Zhang, B.S.; Jia, J.Z. TaCKX6-D1, the ortholog of rice OsCKX2, is associated with grain weight in hexaploid wheat. New Phytol. 2012, 195, 574-584. [CrossRef] [PubMed]

14. Gupta, P.K.; Rustgi, S.; Kumar, N. Genetic and molecular basis of grain size and grain number and its relevance to grain productivity in higher plants. Genome 2006, 49, 565-571. [CrossRef]

15. Varshney, R.K.; Prasad, M.; Roy, J.K.; Kumar, N.; Harjit, S.; Dhaliwal, H.S.; Balyan, H.S.; Gupta, P.K. Identification of eight chromosomes and a microsatellite marker on 1 AS associated with QTL for grain weight in bread wheat. Theor. Appl. Genet. 2000, 100, 1290-1294. [CrossRef]

16. Cao, P.; Liang, X.; Zhao, H.; Feng, B.; Xu, E.; Wang, L.; Hu, Y. Identification of the quantitative trait loci controlling spike-related traits in hexaploid wheat (Triticum aestivum L.). Planta 2019, 250, 1967-1981. [CrossRef]

17. Campbell, B.T.; Baenziger, P.S.; Gill, K.S.; Eskridge, K.M.; Budak, H.; Erayman, M.; Dweikat, I.; Yen, Y. Identification of QTLs and Environmental Interactions Associated with Agronomic Traits on Chromosome 3A of Wheat. Crop Sci. 2003, 43, 1493-1505. [CrossRef]

18. Borner, A.; Schumann, E.; Furste, A.; Coster, H.; Leithold, B.; Roder, S.; Weber, E. Mapping of quantitative trait loci determining agronomic important characters in hexaploid wheat (Triticum aestivum L.). Theor. Appl. Genet. 2002, 105, 921-936. [CrossRef] 
19. Huang, X.Q.; Coster, H.; Ganal, M.W.; Roder, M.S. Advanced backcross QTL analysis for the identification of quantitative trait loci alleles from wild relatives of wheat (Triticum aestivum L.). Theor. Appl. Genet. 2003, 106, 1379-1389. [CrossRef] [PubMed]

20. Huang, X.Q.; Cloutier, S.; Lycar, L.; Radovanovic, N.; Humphreys, D.G.; Noll, J.S.; Somers, D.J.; Brown, P.D. Molecular detection of QTLs for agronomic and quality traits in a doubled haploid population derived from two Canadian wheats (Triticum aestivum L.). Theor. Appl. Genet. 2006, 113, 753-766. [CrossRef] [PubMed]

21. Narasimhamoorthy, B.; Gill, B.S.; Fritz, A.K.; Nelson, J.C.; Brown-Guedira, G.L. Advanced backcross QTL analysis of a hard winter wheat $\times$ synthetic wheat population. Theor. Appl. Genet. 2006, 112, 787-796. [CrossRef] [PubMed]

22. Breseghello, F.; Sorrells, M.E. Association mapping of kernel size and milling quality in wheat (Triticum aestivum L.) cultivars. Genetics 2006, 172, 1165-1177. [CrossRef] [PubMed]

23. Breseghello, F.; Sorrells, M.E. QTL analysis of kernel size and shape in two hexaploid wheat mapping populations. Field Crops Res. 2007, 101, 172-179. [CrossRef]

24. Ramya, P.; Chaubal, A.; Kulkarni, K.; Gupta, L.; Kadoo, N.; Dhaliwal, H.S.; Chhuneja, P.; Lagu, M.; Gupta, V. QTL mapping of 1000-kernel weight, kernel length, and kernel width in bread wheat (Triticum aestivum L.). J. Appl. Genet. 2010, 51, 421-429. [CrossRef] [PubMed]

25. Mir, R.R.; Kumar, N.; Jaiswal, V.; Girdharwal, N.; Prasad, M.; Balyan, H.S.; Gupta, P.K. Genetic dissection of grain weight in bread wheat through quantitative trait locus interval and association mapping. Mol. Breed. 2012, 29, 963-972. [CrossRef]

26. Rasheed, A.; Xia, X.; Ogbonnaya, F.; Mahmood, T.; Zhang, Z.; Mujeeb-Kazi, A.; He, Z. Genome-wide association for grain morphology in synthetic hexaploid wheats using digital imaging analysis. BMC Plant Biol. 2014, 14, 128. [CrossRef] [PubMed]

27. Williams, K.; Munkvold, J.; Sorrells, M. Comparison of digital image analysis using elliptic Fourier descriptors and major dimensions to traits seed shape in hexaploid wheat (Triticum aestivum L.). Euphytica 2012, 190, 99-116. [CrossRef]

28. Zhang, Y.; Liu, J.; Xia, X.; He, Z. TaGS-D1, an ortholog of rice OsGS3, is associated with grain weight and grain length in common wheat. Mol. Breed. 2014, 34, 1097-1107. [CrossRef]

29. Jia, H.; Wan, H.; Yang, S.; Zhang, Z.; Kong, Z.; Xue, S.; Zhang, L.; Ma, Z. Genetic dissection of yield-related traits in a recombinant inbred line population created using a key breeding parent in China's wheat breeding. Theor. Appl. Genet. 2013, 126, 2123-2139. [CrossRef] [PubMed]

30. Guan, P.; Lu, L.; Jia, L.; Kabir, M.R.; Zhang, J.; Lan, T.; Zhao, Y.; Xin, M.; Hu, Z.; Yao, Y.; et al. Global QTL Analysis Identifies Genomic Regions on Chromosomes 4A and 4B Harboring Stable Loci for Yield-Related Traits Across Different Environments in Wheat (Triticum aestivum L.). Front. Plant Sci. 2018, 9, 529. [CrossRef]

31. Cuthbert, J.L.; Somers, D.J.; Brule-Babel, A.L.; Brown, P.D.; Crow, G.H. Molecular mapping of quantitative trait loci for yield and yield components in spring wheat (Triticum aestivum L.). Theor. Appl. Genet. 2008, 117, 595-608. [CrossRef] [PubMed]

32. Mohler, V.; Albrecht, T.; Castell, A.; Diethelm, M.; Schweizer, G.; Hartl, L. Considering causal genes in the genetic dissection of kernel traits in common wheat. J. Appl. Genet. 2016, 57, 467-476. [CrossRef]

33. Brinton, J.; Simmonds, J.; Minter, F.; Leverington-Waite, M.; Snape, J.; Uauy, C. Increased pericarp cell length underlies a major quantitative trait locus for grain weight in hexaploid wheat. New Phytol. 2017, 215, 1026-1038. [CrossRef]

34. Onyemaobi, I.; Ayalew, H.; Liu, H.; Siddique, K.H.M.; Yan, G. Identification and validation of a major chromosome region for high grain number per spike under meiotic stage water stress in wheat (Triticum aestivum L.). PLoS ONE 2018, 13 , e0194075. [CrossRef]

35. Li, F.; Wen, W.; He, Z.; Liu, J.; Jin, H.; Cao, S.; Geng, H.; Yan, J.; Zhang, P.; Wan, Y.; et al. Genome-wide linkage mapping of yield-related traits in three Chinese bread wheat populations using high-density SNP markers. Theor. Appl. Genet. 2018, 131, 1903-1924. [CrossRef]

36. Kumar, A.; Mantovani, E.E.; Seetan, R.; Soltani, A.; Echeverry-Solarte, M.; Jain, S.; Simsek, S.; Doehlert, D.; Alamri, M.S.; Elias, E.M.; et al. Dissection of Genetic Factors underlying Wheat Kernel Shape and Size in an Elite x Nonadapted Cross using a High Density SNP Linkage Map. Plant. Genome 2016, 9, 1. [CrossRef] [PubMed]

37. Wu, Q.H.; Chen, Y.X.; Zhou, S.H.; Fu, L.; Chen, J.J.; Xiao, Y.; Zhang, D.; Ouyang, S.H.; Zhao, X.J.; Cui, Y.; et al. High-density genetic linkage map construction and QTL mapping of grain shape and size in the wheat population Yanda1817 x Beinong6. PLoS ONE 2015, 10, e0118144. [CrossRef] [PubMed]

38. Cui, F.; Zhao, C.; Ding, A.; Li, J.; Wang, L.; Li, X.; Bao, Y.; Li, J.; Wang, H. Construction of an integrative linkage map and QTL mapping of grain yield-related traits using three related wheat RIL populations. Theor. Appl. Genet. 2014, 127, 659-675. [CrossRef]

39. Fan, X.; Cui, F.; Ji, J.; Zhang, W.; Zhao, X.; Liu, J.; Meng, D.; Tong, Y.; Wang, T.; Li, J. Dissection of Pleiotropic QTL Regions Controlling Wheat Spike Characteristics Under Different Nitrogen Treatments Using Traditional and Conditional QTL Mapping. Front. Plant Sci. 2019, 10, 187. [CrossRef]

40. Liu, G.; Jia, L.; Lu, L.; Qin, D.; Zhang, J.; Guan, P.; Ni, Z.; Yao, Y.; Sun, Q.; Peng, H. Mapping QTLs of yield-related traits using RIL population derived from common wheat and Tibetan semi-wild wheat. Theor. Appl. Genet. 2014, 127, 2415-2432. [CrossRef]

41. Liu, J.; Wu, B.; Singh, R.P.; Velu, G. QTL mapping for micronutrients concentration and yield component traits in a hexaploid wheat mapping population. J. Cereal Sci. 2019, 88, 57-64. [CrossRef] [PubMed]

42. Quarrie, S.A.; Steed, A.; Calestani, C.; Semikhodskii, A.; Lebreton, C.; Chinoy, C.; Steele, N.; Pljevljakusic, D.; Waterman, E.; Weyen, J.; et al. A high-density genetic map of hexaploid wheat (Triticum aestivum L.) from the cross Chinese Spring x SQ1 and its use to compare QTLs for grain yield across a range of environments. Theor. Appl. Genet. 2005, 110, 865-880. [CrossRef] 
43. Hai, L.; Guo, H.; Wagner, C.; Xiao, S.; Friedt, W. Genomic regions for yield and yield parameters in Chinese winter wheat (Triticum aestivum L.) genotypes tested under varying environments correspond to QTL in widely different wheat materials. Plant Sci. 2008, 175, 226-232. [CrossRef]

44. Wang, J.; Liu, W.; Wang, H.; Li, L.; Wu, J.; Yang, X.; Li, X.; Gao, A. QTL mapping of yield-related traits in the wheat germplasm 3228. Euphytica 2010, 177, 277-292. [CrossRef]

45. Lee, H.S.; Jung, J.-U.; Kang, C.-S.; Heo, H.-Y.; Park, C.S. Mapping of QTL for yield and its related traits in a doubled haploid population of Korean wheat. Plant Biotechnol. Rep. 2014, 8, 443-454. [CrossRef]

46. Roder, M.S.; Huang, X.Q.; Borner, A. Fine mapping of the region on wheat chromosome 7D controlling grain weight. Funct. Integr. Genom. 2008, 8, 79-86. [CrossRef]

47. Tian, X.; Wen, W.; Xie, L.; Fu, L.; Xu, D.; Fu, C.; Wang, D.; Chen, X.; Xia, X.; Chen, Q.; et al. Molecular Mapping of Reduced Plant Height Gene Rht24 in Bread Wheat. Front. Plant Sci. 2017, 8, 1379. [CrossRef]

48. Mo, Y.; Vanzetti, L.S.; Hale, I.; Spagnolo, E.J.; Guidobaldi, F.; Al-Oboudi, J.; Odle, N.; Pearce, S.; Helguera, M.; Dubcovsky, J. Identification and characterization of Rht25, a locus on chromosome arm 6AS affecting wheat plant height, heading time, and spike development. Theor. Appl. Genet. 2018, 131, 2021-2035. [CrossRef]

49. Agarwal, P.; Balyan, H.S.; Gupta, P.K. Identification of modifiers of the plant height in wheat using an induced dwarf mutant controlled by RhtB4c allele. Physiol. Mol. Biol. Plants 2020, 26, 2283-2289. [CrossRef] [PubMed]

50. Zhang, J.; Dell, B.; Biddulph, B.; Drake-Brockman, F.; Walker, E.; Khan, N.; Wong, D.; Hayden, M.; Appels, R. Wild-type alleles of Rht-B1 and Rht-D1 as independent determinants of thousand-grain weight and kernel number per spike in wheat. Mol. Breed. 2013, 32, 771-783. [CrossRef]

51. Chai, L.; Chen, Z.; Bian, R.; Zhai, H.; Cheng, X.; Peng, H.; Yao, Y.; Hu, Z.; Xin, M.; Guo, W.; et al. Dissection of two quantitative trait loci with pleiotropic effects on plant height and spike length linked in coupling phase on the short arm of chromosome 2D of common wheat (Triticum aestivum L.). Theor. Appl. Genet. 2019, 132, 1815-1831. [CrossRef]

52. Chen, Z.; Cheng, X.; Chai, L.; Wang, Z.; Bian, R.; Li, J.; Zhao, A.; Xin, M.; Guo, W.; Hu, Z.; et al. Dissection of genetic factors underlying grain size and fine mapping of QTgw.cau-7D in common wheat (Triticum aestivum L.). Theor. Appl. Genet. 2020, 133, 149-162. [CrossRef]

53. Sun, C.; Dong, Z.; Zhao, L.; Ren, Y.; Zhang, N.; Chen, F. The Wheat 660K SNP array demonstrates great potential for markerassisted selection in polyploid wheat. Plant Biotechnol. J. 2020, 18, 1354-1360. [CrossRef] [PubMed]

54. Wang, S.; Chen, J.; Zhang, W.; Hu, Y.; Chang, L.; Fang, L.; Wang, Q.; Lv, F.; Wu, H.; Si, Z.; et al. Sequence-based ultra-dense genetic and physical maps reveal structural variations of allopolyploid cotton genomes. Genome Biol. 2015, 16, 108. [CrossRef]

55. Schwarzkopf, E.J.; Motamayor, J.C.; Cornejo, O.E. Genetic differentiation and intrinsic genomic features explain variation in recombination hotspots among cocoa tree populations. BMC Genom. 2020, 21, 332. [CrossRef]

56. Cavanagh, C.R.; Chao, S.; Wang, S.; Huang, B.E.; Stephen, S.; Kiani, S.; Forrest, K.; Saintenac, C.; Brown-Guedira, G.L.; Akhunova, A.; et al. Genome-wide comparative diversity uncovers multiple targets of selection for improvement in hexaploid wheat landraces and cultivars. Proc. Natl. Acad. Sci. USA 2013, 110, 8057-8062. [CrossRef]

57. Wang, S.; Wong, D.; Forrest, K.; Allen, A.; Chao, S.; Huang, B.E.; Maccaferri, M.; Salvi, S.; Milner, S.G.; Cattivelli, L.; et al. Characterization of polyploid wheat genomic diversity using a high-density 90,000 single nucleotide polymorphism array. Plant Biotechnol. J. 2014, 12, 787-796. [CrossRef]

58. Sun, C.; Zhang, F.; Yan, X.; Zhang, X.; Dong, Z.; Cui, D.; Chen, F. Genome-wide association study for 13 agronomic traits reveals distribution of superior alleles in bread wheat from the Yellow and Huai Valley of China. Plant Biotechnol. J. 2017, 15, 953-969. [CrossRef] [PubMed]

59. Winfield, M.O.; Allen, A.M.; Burridge, A.J.; Barker, G.L.; Benbow, H.R.; Wilkinson, P.A.; Coghill, J.; Waterfall, C.; Davassi, A.; Scopes, G.; et al. High-density SNP genotyping array for hexaploid wheat and its secondary and tertiary gene pool. Plant Biotechnol. J. 2016, 14, 1195-1206. [CrossRef] [PubMed]

60. Liu, S.; Huang, S.; Zeng, Q.; Wang, X.; Yu, R.; Wang, Q.; Singh, R.P.; Bhavani, S.; Kang, Z.; Wu, J.; et al. Refined mapping of stripe rust resistance gene YrP10090 within a desirable haplotype for wheat improvement on chromosome 6A. Theor. Appl. Genet. 2021, 3, 1-17.

61. Liu, J.; Luo, W.; Qin, N.; Ding, P.; Zhang, H.; Yang, C.; Mu, Y.; Tang, H.; Liu, Y.; Li, W.; et al. A 55 K SNP array-based genetic map and its utilization in QTL mapping for productive tiller number in common wheat. Theor. Appl. Genet. 2018, 131, 2439-2450. [CrossRef]

62. Ma, J.; Zhang, H.; Li, S.; Zou, Y.; Li, T.; Liu, J.; Ding, P.; Mu, Y.; Tang, H.; Deng, M.; et al. Identification of quantitative trait loci for kernel traits in a wheat cultivar Chuannong16. BMC Genet. 2019, 20, 77. [CrossRef] [PubMed]

63. Ma, J.; Ding, P.; Liu, J.; Li, T.; Zou, Y.; Habib, A.; Mu, Y.; Tang, H.; Jiang, Q.; Liu, Y.; et al. Identification and validation of a major and stably expressed QTL for spikelet number per spike in bread wheat. Theor. Appl. Genet. 2019, 132, 3155-3167. [CrossRef]

64. Ren, T.; Hu, Y.; Tang, Y.; Li, C.; Yan, B.; Ren, Z.; Tan, F.; Tang, Z.; Fu, S.; Li, Z. Utilization of a Wheat55K SNP Array for Mapping of Major QTL for Temporal Expression of the Tiller Number. Front. Plant Sci. 2018, 9, 333. [CrossRef] [PubMed]

65. Huang, S.; Wu, J.; Wang, X.; Mu, J.; Xu, Z.; Zeng, Q.; Liu, S.; Wang, Q.; Kang, Z.; Han, D. Utilization of the Genomewide Wheat 55K SNP Array for Genetic Analysis of Stripe Rust Resistance in Common Wheat Line P9936. Phytopathology 2019, 109, 819-827. [CrossRef] [PubMed]

66. Rasheed, A.; Xia, X. From markers to genome-based breeding in wheat. Theor. Appl. Genet. 2019, 132, 767-784. [CrossRef] 
67. Cui, F.; Fan, X.; Chen, M.; Zhang, N.; Zhao, C.; Zhang, W.; Han, J.; Ji, J.; Zhao, X.; Yang, L.; et al. QTL detection for wheat kernel size and quality and the responses of these traits to low nitrogen stress. Theor. Appl. Genet. 2016, 129, 469-484. [CrossRef]

68. Hao, C.; Jiao, C.; Hou, J.; Li, T.; Liu, H.; Wang, Y.; Zheng, J.; Liu, H.; Bi, Z.; Xu, F.; et al. Resequencing of 145 Landmark Cultivars Reveals Asymmetric Sub-genome Selection and Strong Founder Genotype Effects on Wheat Breeding in China. Mol. Plant 2020, 12, 1733-1751. [CrossRef]

69. Brinton, J.; Ramirez-Gonzalez, R.H.; Simmonds, J.; Wingen, L.; Orford, S.; Griffiths, S.; Wheat Genome, P.; Haberer, G.; Spannagl, M.; Walkowiak, S.; et al. A haplotype-led approach to increase the precision of wheat breeding. Commun. Biol. 2020, 3, 712. [CrossRef]

70. Meng, L.; Li, H.; Zhang, L.; Wang, J. QTL IciMapping: Integrated software for genetic linkage map construction and quantitative trait locus mapping in biparental populations. Crop J. 2015, 3, 269-283. [CrossRef]

71. Cui, F.; Zhang, N.; Fan, X.L.; Zhang, W.; Zhao, C.H.; Yang, L.J.; Pan, R.Q.; Chen, M.; Han, J.; Zhao, X.Q.; et al. Utilization of a Wheat660K SNP array-derived high-density genetic map for high-resolution mapping of a major QTL for kernel number. Sci. Rep. 2017, 7, 3788. [CrossRef] [PubMed]

72. Wu, J.; Yu, R.; Wang, H.; Zhou, C.; Huang, S.; Jiao, H.; Yu, S.; Nie, X.; Wang, Q.; Liu, S.; et al. A large-scale genomic association analysis identifies the candidate causal genes conferring stripe rust resistance under multiple field environments. Plant Biotechnol. J. 2021, 19, 177-191. [CrossRef] [PubMed]

73. Banta, J.A.; Stevens, M.H.H.; Pigliucci, M. A comprehensive test of the 'limiting resources' framework applied to plant tolerance to apical meristem damage. Oikos 2010, 119, 359-369. [CrossRef]

74. Wu, Y.; Bhat, P.R.; Close, T.J.; Lonardi, S. Efficient and accurate construction of genetic linkage maps from the minimum spanning tree of a graph. PLoS Genet. 2008, 4, e1000212. [CrossRef] [PubMed]

75. Yu, L.; He, F.; Chen, G.L.; Cui, F.; Li, X.F. Identification of 1BL·1RS Wheat-Rye Chromosome Translocations via 1RS Specific Molecular Markers and Genomic in situ Hybridization. Acta Agron. Sin. 2011, 37, 563-569. [CrossRef] 